\title{
Rapid screening for Chlamydia trachomatis infection by detecting a-mannosidase activity in urogenital tract specimens
}

\author{
Ze-yu Wang ${ }^{1}$, Guang-yu Fu', Shan-mei Wang ${ }^{2}$, Dong-chun Qin³ ${ }^{3}$ Zhong-quan Wang ${ }^{1}$ and Jing Cui ${ }^{*}$
}

\begin{abstract}
Background: Chlamydia trachomatis may cause multiple different urogenital tract disorders, but current non-culture assays for rapid screening of $C$. trachomatis typically use immunochromatography-based methods. We established another new rapid non-culture method for detection of $C$. trachomatis based on the measurement of a-mannosidase enzymatic activity in urogenital tract specimens.

Method: To evaluate the performance of this method, a-mannosidase activities of $C$. trachomatis serotype $D$ strain 、 and 29 standard strains related to clinical urogenital pathogens were investigated. Furthermore, 553 urogenital tract specimens were used for clinical assays via cell culture method and ligase chain reaction method (LCR), adopting an expanded gold standard.
\end{abstract}

Results: Only C. trachomatis was positive for a-mannosidase activity among different types of microbes tested in the research. When prostate fluid specimens, which have some interfering activity, were excluded, the sensitivity and specificity of the enzymatic method were $91.8 \%$ (78/85) and 98.3\% (409/416), respectively. There were no significant differences $(P>0.05)$.

Conclusions: These results showed that a-mannosidase activity could be utilised as a screening marker of $C$. trachomatis infection.

Keywords: Chlamydia trachomatis, a-mannosidase, Activity, Gold standard, Marker

\section{Background}

C. trachomatis infection is the most common sexually transmitted disease (STD) in the United States [1]. Mounting evidence has indicated that it not only evokes nongonococcal urethritis (NGU), cervicitis, pelvic inflammatory disease (PID), salpingitis, orchitis, and epididymitis, but also increases risk of invasive cervical cancer $[2,3]$ and gives rise to serious reproductive disorders such as infertility [4,5], miscarriage/premature birth/missed miscarriage [6-9], and neonatal conjunctivitis [10].

A large number of methods have been established for screening and diagnosis of C. trachomatis infection [11]. Nevertheless, few of these assays meet the requirements of outpatient diagnosis, especially in terms of sensitivity, specificity, time, and simplicity of operation. Currently, non-culture assays for $C$. trachomatis screening typically adopt immunochromatography-based methods. Technologies based on chromogenic reactions of specific microbial enzymes have been widely applied in bacterial identification systems and chromogenic media [12-15]. However, no chromogenic assay for detecting C. trachomatis has been made available to date.

Our previous findings [16] suggested that $C$. trachomatis might have very high $\alpha$-mannosidase activity. The purpose of the study was to establish a novel screening method for C. trachomatis infection without culture that would be rapid and convenient for use in outpatient clinics.

\footnotetext{
* Correspondence: pine8844@126.com

'Department of Pathogen Biology, School of Basic Medicine, Zhengzhou University, Zhengzhou 450001, China

Full list of author information is available at the end of the article
} 


\section{Methods}

\section{Ethics statement}

All patients were treated in accordance with the Helsinki Declaration on the participation of human subjects in medical research. Ethics approval for the study was obtained from the First Affiliated Hospital Ethics Committee of Zhengzhou University (Approved No. 20100802) and Henan Provincial People's Hospital Ethics Committee (Approved No. 20100901).

\section{Organisms}

Reference strains and cell lines were obtained from the organisations shown in Table 1.

\section{Specimens}

This study evaluated 553 specimens from clinical patients attending the STD (257, 46.47\%) and Gynaecology (296, 53.53\%) clinics at the First Affiliated Hospital of Zhengzhou University (Zhengzhou, China) and the Henan Provincial People's Hospital (Zhengzhou, China), respectively. For the 203 male cases, three urethral discharge specimens (151 outpatients, 74.38\%) or three prostate massage liquid specimens (52 outpatients, 25.62\%) were collected with sterile rayon swabs (Copan, Brescia, Italy). Meanwhile, for the 350 female cases, three cervical secretion specimens (232 outpatients, 66.29\%) or three vaginal secretion specimens (118 outpatients, 33.71\%) were collected with sterile rayon swabs using vaginal forceps.

Table 1 Reference strains and cell line

\begin{tabular}{|c|c|c|}
\hline Strains or cell line & Accession numbers & Organizations \\
\hline Acinetobacter baumannii & ATCC19606 & Harmony Biotechnology Co., Ltd (Shanghai, China) \\
\hline Candida albicans & ATCC10231 & Harmony Biotechnology Co., Ltd (Shanghai, China) \\
\hline Candida glabrata & ATCC15126 & Harmony Biotechnology Co., Ltd (Shanghai, China) \\
\hline Candida guilliermondii & ATCC6260 & Harmony Biotechnology Co., Ltd (Shanghai, China) \\
\hline Candida krusei & ATCC14243 & Harmony Biotechnology Co., Ltd (Shanghai, China) \\
\hline Cryptococcus neoformans & CMCC(F)D2q & China Medical Microbiological Culture Collection Center (fungi)(Nanjing, China) \\
\hline Candida parapsilosis & CGMCC2.1846 & China General Microbiological Culture Collection Center (Beijing, China) \\
\hline Candida tropicalis & ATCC750 & Harmony Biotechnology Co., Ltd (Shanghai, China) \\
\hline Chlamydia trachomatis Serovar D & VR-885 & American Type Culture Collection(Manassas, USA) \\
\hline Enterococcus faecalis & ATCC29212 & Huankai Microbial Sci \& Tech. Co., Ltd (Guangzhou, China) \\
\hline Enterococcus faecium & ATCC700221 & Harmony Biotechnology Co., Ltd (Shanghai, China) \\
\hline Escherichia coli & ATCC25922 & Henan Provincial Institute of Food and Drug Control (Zhengzhou, China) \\
\hline Gardnerella vaginalis & ATCC 14018 & Harmony Biotechnology Co., Ltd (Shanghai, China) \\
\hline Haemophilus influenzae & ATCC10211 & Harmony Biotechnology Co., Ltd (Shanghai, China) \\
\hline Klebsiella pneumoniae & CMCC46117 & Tianhe Microorganism Reagent Co., Ltd (Hangzhou, China) \\
\hline McCony & CRL-1696 & American Type Culture Collection(Manassas, USA) \\
\hline Mycoplasma hominis & ATCC15488 & Harmony Biotechnology Co., Ltd (Shanghai, China) \\
\hline Neisseria gonorrhoeae & ATCC19424 & Henan Provincial Center for Disease Control and Prevention (Zhengzhou, China) \\
\hline Pseudomonas aeruginosa & ATCC25619 & Land Bridge Biotechnology Co., Ltd (Beijing, China) \\
\hline Proteus mirabilis & CMCC(B)49005 & Huankai Microbial Sci \& Tech. Co., Ltd (Guangzhou, China) \\
\hline Salmonella enteritidis & ATCC13076 & Land Bridge Biotechnology Co., Ltd (Beijing, China) \\
\hline Staphylococus aureus & ATCC25923 & Henan Provincial Institute of Food and Drug Control (Zhengzhou, China) \\
\hline Staphylococcus aureus & ATCC29213 & Capital Institute of Pediatrics (Beijing, China) \\
\hline Staphylococcus epidermidis & ATCC 12228 & Huankai Microbial Sci \& Tech. Co., Ltd (Guangzhou, China) \\
\hline Staphylococus saprophyticus & ATCC49453 & Land Bridge Biotechnology Co., Ltd (Beijing, China) \\
\hline Stenotrophomonas maltophilia & ATCC17666 & Land Bridge Biotechnology Co., Ltd (Beijing, China) \\
\hline Streptococus agalactiae & ATCC13813 & Harmony Biotechnology Co., Ltd (Shanghai, China) \\
\hline Streptococus pneumoniae & ATCC49619 & National Center for Clinical Laboratory (Beijing, China) \\
\hline Streptococus pyogenes & ATCC19615 & Harmony Biotechnology Co., Ltd (Shanghai, China) \\
\hline Trichomonas vaginalis & ATCC 30001 & Harmony Biotechnology Co., Ltd (Shanghai, China) \\
\hline Ureaplasma urealyticum & ATCC15531 & Harmony Biotechnology Co., Ltd (Shanghai, China) \\
\hline
\end{tabular}


Three swabs collected for each specimen, were no significant differences in sampling link and randomly used with three methods. None of the patients received any antibiotics one week before sample collection, when samples were taken before diagnosis.

\section{Media, culture and inoculation}

Liquid media A (LMA) and liquid media B (LMB) were prepared for mycoplasma culture. The components of LMA were shown in Table 2, but LMB consisted of $50 \mathrm{mg} / \mathrm{l}$ phenol red besides LMA components. The media were inoculated with both Ureaplasma urealyticum and Mycoplasma hominis and analyzed by using the colourchanging unit (CCU) method, as previously reported [17]. Once the concentrations of mycoplasma reached $10^{6}$ $\mathrm{CCU} / \mathrm{ml}$ in LMB, the cultures of LMA should be immediately stored at $4^{\circ} \mathrm{C}$.

Trichomonas vaginalis was obtained after $24 \mathrm{~h}$ incubation at $37^{\circ} \mathrm{C}$ in Trichomonas medium (Oxoid, Basingstoke, UK) supplemented with $8 \%$ horse blood and 1,000 units $/ \mathrm{ml}$ penicillin sodium and $500 \mathrm{mg} / \mathrm{ml}$ streptomycin. The collection was stored at $4{ }^{\circ} \mathrm{C}$.

All other micro-organisms except C. trachomatis used in the study were inoculated and cultured as described in Table 3. The collections described in Table 3 were resuspended to $0.5 \mathrm{McF}$ arland standards in a sterile solution of $0.9 \% \mathrm{NaCl}$ and then stored at $4{ }^{\circ} \mathrm{C}$.

\section{Enzymatic method}

The enzymatic method was based on the substrate of $\alpha-D$-mannosidase. The substrate solution contained $1.5 \mathrm{mg} / \mathrm{ml}$ 6-chloro-3-indolyl- $\alpha$-D-mannoside (J\&K, Shanghai, China), $100 \mathrm{mM}$ citrate buffer ( $\mathrm{pH} 4.0$ ), and $1 \%$ Triton $\mathrm{X}-100$. The sample diluent was $0.9 \% \mathrm{NaCl}$. The chromogenic reagent contained $0.08 \%$ fast violet $\mathrm{B}$

Table 2 Composition of LMA for Mycoplasma (per liter) *

\begin{tabular}{lclc}
\hline Ingredient & Concentration & Ingredient & Concentration \\
\hline $\mathrm{NaCl}$ & $6.4 \mathrm{~g}$ & $\begin{array}{l}\text { Beef heart extract } \\
\text { power }\end{array}$ & $7.2 \mathrm{~g}$ \\
$\mathrm{CaCl}_{2}$ & $112 \mathrm{mg}$ & $\begin{array}{l}\text { Yeast extract } \\
\text { power }\end{array}$ & $2.72 \mathrm{~g}$ \\
$\mathrm{MgCl}_{2} \cdot 6 \mathrm{H}_{2} \mathrm{O}$ & $80 \mathrm{mg}$ & Peptone & $8.0 \mathrm{~g}$ \\
$\mathrm{MgSO}_{4} \cdot 7 \mathrm{H}_{2} \mathrm{O}$ & $80 \mathrm{mg}$ & Horse serum & $200 \mathrm{ml}$ \\
$\mathrm{KCl}$ & $320 \mathrm{mg}$ & Penicillin sodium & $1,000,000 \mathrm{units}$ \\
$\mathrm{Na}_{2} \mathrm{HPO}_{4} \cdot 12 \mathrm{H}_{2} \mathrm{O}$ & $122 \mathrm{mg}$ & Ampicillin sodium & $375 \mathrm{mg}$ \\
$\mathrm{KH}_{2} \mathrm{PO}_{4}$ & $48 \mathrm{mg}$ & Vancomycin & $40 \mathrm{mg}$ \\
$\mathrm{Cysteine}_{\text {hydrochloride }}$ & $0.8 \mathrm{~g}$ & Polymyxin B & $40,000 \mathrm{units}$ \\
Arginine & & & $15,000 \mathrm{USP}$ \\
hydrochloride & $4.0 \mathrm{~g}$ & Nystatin & units \\
Urea & & &
\end{tabular}

${ }^{*}$ Adjusted to $\mathrm{pH} 6.25$. salt (J\&K, Shanghai, China). Aliquots $(50 \mu \mathrm{l})$ of substrate solution and chromogenic reagent were added sequentially into sample solutions (extracted from every swab sample with $500 \mu \mathrm{l}$ sample diluent) or the aforementioned microbial suspensions as well as the chlamydial suspension mentioned in the section called limit of detection (LOD) of the enzymatic method. The result was considered to be positive $\left(\mathrm{OD}_{512} \geqq 0.150\right)$ if the colour changed from colourless to red or brown after $15 \mathrm{~min}$ of incubation at $37^{\circ} \mathrm{C}$; otherwise, the result was considered to be negative $\left(\mathrm{OD}_{512}<0.150\right)$. The suspensions containing bacteria or cells was centrifuged at 5,000 rpm for $5 \mathrm{~min}$, and then $\mathrm{OD}_{512}$ value of the supernatants were measured.

\section{LOD of the enzymatic method}

McCoy cells infected with C. trachomatis serovar D were stored at $-80^{\circ} \mathrm{C}$, and frozen-thawed twice to obtain chlamydial suspension before use. Serial 10-fold dilutions of the chlamydial suspension were inoculated in six duplicate into wells $(100 \mu \mathrm{l} /$ well $)$ of cycloheximide-treated McCoy cell monolayers that had been incubated with MEM medium (Gibco, Grand Island, NY, USA) in a 96-well flat-bottom microtiter plate (Nunc Inc., Roskilde, Denmark) at $37^{\circ} \mathrm{C}$ under $5 \% \mathrm{CO}_{2}$ for $48 \mathrm{~h}$. Inclusion body titers of the chlamydial supernatant were quantified by titrating the number of inclusion-forming units (IFU). The contents of each well were stained with a C. trachomatis direct fluorescent antibody kit (Academy of Military Medical Science, Beijing, China) and examined by microscopy for IFU counts. The average IFU of each dilution culture of three replicate wells was taken as the concentration of $C$. trachomatis in the corresponding dilution of the chlamydia suspension. Each dilution culture of the other three replicate wells was examined via the enzymatic method after collection to determine the LOD for $C$. trachomatis of the enzymatic method. $10^{-1} \mathrm{u} / \mathrm{ml} \alpha$-D-mannosidase (EC3.2.1.24; Sigma, USA) solution was 5-fold serially diluted to $10^{-4} \mathrm{u} / \mathrm{ml}$. These enzyme solutions fold-diluted were detected via the enzymatic method to determine the LOD for $\alpha-D$ mannosidase.

\section{Reference method}

Cell culture and LCR method were used to evaluate the clinical performance of the enzymatic method. The swabs used for culture were dipped directly into incidental transport medium (Copan, Brescia, Italy) and cultured according to the aforementioned method. The cultures were tested using a $C$. trachomatis direct fluorescent antibody kit. LCR was carried out using the LCx C. trachomatis assay (Abbott Laboratories, Abbott Park, Israel) according to the manufacturer's instructions. Although culture method has a good specificity, its sensitivity may be influenced by various factors. 
Table 3 The media and culture methods for bacteria and candida

\begin{tabular}{|c|c|c|c|}
\hline$\underline{\text { Strains }}$ & Media & Temp. & Time \\
\hline \multicolumn{4}{|l|}{ Bacteria } \\
\hline A. baumannii, E. faecalis, & Blood agar base ${ }^{a}$ & $37^{\circ} \mathrm{C}$ & $24 \mathrm{~h}$ \\
\hline \multicolumn{4}{|l|}{$\begin{array}{l}\text { E. faecium, E. coli, } K \text {. } \\
\text { pneumoniae, }\end{array}$} \\
\hline \multicolumn{4}{|l|}{ P. mirabilis, $P$. aeruginosa, } \\
\hline \multicolumn{4}{|l|}{ S. enteritidis, S. aureus, } \\
\hline \multicolumn{4}{|l|}{ S. epidermidis, S. saprophyticus, } \\
\hline \multicolumn{4}{|l|}{ S. maltophilia, S. agalactiae, } \\
\hline \multicolumn{4}{|l|}{ S. pyogenes, S. pneumoniae } \\
\hline G. vaginalis * & Blood agar base & $37^{\circ} \mathrm{C}$ & $48 \mathrm{~h}$ \\
\hline H. influenzae * & Thayer Martin media ${ }^{b}$ & & $24 \mathrm{~h}$ \\
\hline N. gonorrhoeae * & & & $48 \mathrm{~h}$ \\
\hline \multicolumn{4}{|l|}{ Candida } \\
\hline C. albicans, C. tropicalis, & Sabouraud dextrose & $37^{\circ} \mathrm{C}$ & $24 \mathrm{~h}$ \\
\hline C. glabrata, C. parapsilosis, & & & \\
\hline \multicolumn{4}{|l|}{ C. guilliermondii, C. krusei, } \\
\hline C. neoformans & & $30^{\circ} \mathrm{C}$ & $48 \mathrm{~h}$ \\
\hline
\end{tabular}

Therefore, the research adopted an "expanded gold standard" [18-20] described as follows: any positive by either culture or LCR was classified as a true positive, whatever the result of the enzymatic method.

\section{Results}

In our developed assay, only $C$. trachomatis samples tested was positive for $\alpha$-D-mannosidase activity; but $\mathrm{OD}_{512}$ of both other organisms and cell cultures which were not inoculated with $C$. trachomatis used in the study was all below 0.100 , which fell into the range of negative results negative with $0.150\left(\mathrm{OD}_{512}\right)$ as the cutoff value, even if the reactions were allowed to proceed for $1 \mathrm{~h}$ at $37^{\circ} \mathrm{C}$. Of the 553 clinical samples, 132 samples were positive with $\mathrm{OD}_{512}$ ranging from 0.161 to 1.955 , and 421 samples were negative with $\mathrm{OD}_{512}$ ranging from 0.013 to 0.142 . C. trachomatis detection results of 553 cases with culture, LCR and enzymatic method used an expanded gold standard as the reference standard were showed in Table 4. The enzymatic method was least reliable when prostate specimens were used. The sensitivity of the enzymatic method was $91.5 \%$ (95\% confidence interval [CI], $85.9 \%$ to $97.1 \%$ ), and the specificity of this method was $90.0 \%$ (95\% CI, $87.3 \%$ to $92.7 \%$ ) (Table 5). The sensitivity and specificity of the LCR were $94.7 \%$ (95\% CI, $90.2 \%$ to $99.2 \%$ ) and $100 \%$ (95\% CI, $100.0 \%$ to $100.0 \%)$, respectively. However, in those specimens other than prostate fluid samples, the sensitivity and specificity of the enzymatic method were $91.8 \%$ (95\% CI, $86.0 \%$ to
97.6\%) and $98.3 \%$ (95\% CI, 97.1\% to 99.5\%), in the meantime the sensitivity and specificity of the LCR were 95.3\% (95\% CI, $90.8 \%$ to $99.8 \%$ ) and $100 \%$ (95\% CI, $100 \%$ to $100 \%$ ) (Table 6), respectively. There were no significant differences in performance between the enzymatic method and the expanded gold standard $(P>0.05)$.

The result of the chlamydial suspension quantified with 617 IFU/ml was light pink, and might be considered positive $\left(\mathrm{OD}_{512}=0.162\right)$. Meanwhile, the result of the chlamydial suspension was colourless if quantified with $126 \mathrm{IFU} / \mathrm{ml}$, and might be considered negative $\left(\mathrm{OD}_{512}=0.098\right)$. Therefore, the LOD was $617 \mathrm{IFU} / \mathrm{ml}$ for $C$. trachomatis. In addition, the LOD was $10^{-3} \mathrm{u} / \mathrm{ml}$ $\left(\mathrm{OD}_{512}=0.155\right)$ for $\alpha-\mathrm{D}$-mannosidase.

\section{Discussion}

There are various well-known methods for detecting C. trachomatis, including cell culture-, immunology-, molecular biology-, and biochemistry-based methods. Cell culture is complicated to perform and requires experience to produce accurate results, and it also has more stringent requirements for the sampling swabs and transporting before inoculation [21,22]. Therefore, cell culture is rarely used in clinics. Among the available immunological methods, serological tests for the C. trachomatis antibody have significant limitations [23], but methods for $C$. trachomatis antigen detection (mainly referring to the lipopolysaccharide, LPS), especially immunochromatography-based methods, have been widely used due to their simplicity of operation. There are two ways to extract the LPS antigen for C. trachomatis immunochromatographic assays: heat extraction and acid extraction. Neither of these methods guarantees the full extraction of LPS as an intact antigen, which influences the sensitivity of this method. The biochemical detection of glycogen in C. trachomatis inclusions [24] is greatly affected by Candida spp. that often exist in these specimens and are especially common during the female menstrual cycle and pregnancy. With the increasing glycogen in vaginal epithelial cells, this method may also cause false positives. The detection of C. trachomatis in the United States and Europe has mainly focused on molecular biology methods [25-30]. Although these methods are both high sensitivity and high specificity, it can be challenging for molecular biology methods to meet the requirements of the actual application in clinical screening.

Enzymatic studies of $C$. trachomatis, especially for enzymes with diagnostic significance, have not been reported in the literature. Previous studies [31] and our research have shown that $C$. trachomatis secretes extracellular enzymes with high $\alpha$-D-mannosidase activity. Although some organisms used in the study such as C. albicans have genes encoding $\alpha-1,2$-mannosidase 
Table 4 C. trachomatis detection results of 553 cases with culture, LCR and enzymatic method used an expanded gold standard as the reference standard

\begin{tabular}{|c|c|c|}
\hline Method & No. of true positives/positives & No. of true negatives/negatives \\
\hline \multirow[t]{5}{*}{ Enzymatic method } & $86 / 132$ & $413 / 421$ \\
\hline & Urethral discharge 22/24 & Urethral discharge 126/127 \\
\hline & Prostate massage liquid 8/47 & Prostate massage liquid $4 / 5$ \\
\hline & Cervical secretion 31/33 & Cervical secretion 196/199 \\
\hline & Vaginal secretion $25 / 28$ & Vaginal secretion $87 / 90$ \\
\hline \multirow[t]{5}{*}{ Cell culture } & $60 / 60$ & $459 / 493$ \\
\hline & Urethral discharge 18/18 & Urethral discharge 128/133 \\
\hline & Prostate massage liquid $7 / 7$ & Prostate massage liquid $43 / 45$ \\
\hline & Cervical secretion 21/21 & Cervical secretion 198/211 \\
\hline & Vaginal secretion 14/14 & Vaginal secretion 90/104 \\
\hline \multirow[t]{5}{*}{ LCR } & $85 / 89$ & $459 / 464$ \\
\hline & Urethral discharge 22/22 & Urethral discharge 128/133 \\
\hline & Prostate massage liquid $8 / 8$ & Prostate massage liquid $43 / 45$ \\
\hline & Cervical secretion 32/32 & Cervical secretion 198/211 \\
\hline & Vaginal secretion $27 / 27$ & Vaginal secretion 90/104 \\
\hline \multirow[t]{5}{*}{ Expanded gold standard } & 94 & 459 \\
\hline & Urethral discharge 23 & Urethral discharge 128 \\
\hline & Prostate massage liquid 9 & Prostate massage liquid 43 \\
\hline & Cervical secretion 34 & Cervical secretion 198 \\
\hline & Vaginal secretion 28 & Vaginal secretion 90 \\
\hline
\end{tabular}

[32], $\alpha$-D-mannosidase activity was invisible by naked eyes with 6-chloro-3-indolyl- $\alpha$-D-mannoside as substrate. This may be because the extracellular $\alpha$-D-mannosidase from these organisms is much less or the enzyme activity is relatively low. Previous records [31,33-35] on substrates of $\alpha$-D-mannosidase mainly involved p-nitrophenol- $\alpha$-D-mannoside and 4-methylumbelliferyl- $\alpha$-D-mannoside. However, 6-chloro-3-indolyl- $\alpha-D$-mannoside is a novel chromogenic substrate, and colour reaction of its chromogen is much more sensitive especially in the case of the presence of an azo reagent such as fast violet B salt. Our results showed that clinical specimens such as urethral discharge, cervical secretions, and vaginal secretions did not interfere with the chromogenic detection of $\alpha$-D-mannosidase activity to screen for C. trachomatis, although prostate massage liquid produced more

Table $\mathbf{5}$ Clinical performances of three assays for $\boldsymbol{C}$. trachomatis using specimens included prostate massage liquid

\begin{tabular}{lcc}
\hline Methods & \% Sensitivity (95\% Cl) & \% Specificity (95\% CI) \\
\hline Enzymatic method $^{a}$ & $91.5(85.9,97.1)$ & $90.0(87.3,92.7)$ \\
Cell culture $^{b}$ & $63.8(54.1,73.5)$ & $100.0(100.0,100.0)$ \\
LCR $^{c}$ & $94.7(90.2,99.2)$ & $100.0(100.0,100.0)$ \\
\hline${ }^{a} X^{2}=8.030, P=0.005, P<0.05 ;^{b} X^{2}=8.721, P=0.003, P<0.05 ;{ }^{c} X^{2}=0.164$, \\
$P=0.685, P>0.05$.
\end{tabular}

false positive results. Some human sperm surface proteins possess $\alpha-D$-mannosidase activity [36], which may be the reason that prostate specimens produce less reliable results. Serotype D was only one of the most prevalent (11.1\%), and no serovar L2 was found in China [37]. Although the results of this study suggested that other serotypes, such as serotypes E, F, G, K, H, J, I, and Ba, at least most of them, might have $\alpha$-D-mannosidase activity, there seems to be some limitation of tests on C. trachomatis cultures based on only one strain of serotype D. Further studies and more comprehensive clinical evaluations should be conducted due to little research on $\alpha$-D-mannosidase activity of $C$. trachomatis. In addition, our studies did not evaluate C. pneumoniae or C. psittaci; the $\alpha-\mathrm{D}$-mannosidase activities of these species should be studied as well.

Table 6 Clinical performances of three assays for $C$. trachomatis using specimens excluded prostate massage liquid

\begin{tabular}{lcc}
\hline Methods & \% Sensitivity $(\mathbf{9 5 \%} \mathrm{Cl})$ & \% Specificity $(\mathbf{9 5 \%} \mathrm{Cl})$ \\
\hline Enzymatic method $^{\mathrm{a}}$ & $91.8(86.0,97.6)$ & $98.3(97.1,99.5)$ \\
Cell culture $^{\mathrm{b}}$ & $64.6(54.3,74.9)$ & $100.0(100.0,100.0)$ \\
$\mathrm{LCR}^{\mathrm{C}}$ & $95.3(90.8,99.8)$ & $100.0(100.0,100.0)$ \\
\hline${ }^{\mathrm{a}} \mathrm{X}^{2}=0, P=1, P>0.05 ;{ }^{\mathrm{b}} \mathrm{X}^{2}=8.605, P=0.003, P<0.05 ;{ }^{\mathrm{c}} \mathrm{X}^{2}=0.116$, \\
$P=0.734, P>0.05$.
\end{tabular}




\section{Conclusions}

The present study demonstrated that there were no significant differences between the enzymatic method and the reference method when prostate specimens were excluded. Therefore, $\alpha$-D-mannosidase activity may be a useful marker for $C$. trachomatis in urogenital tract specimens, with many advantages, such as its speed, ease of use, convenience, and need for no special equipment. Taken together, these data show that the enzymatic method has great potential as a clinical method for C. trachomatis screening.

\section{Competing interests}

The authors declare that they have no competing interests. We are applying for one patent (CN patent 102286608A) relating to the content of the manuscript, and the authors do not have any objection on the patent right of authorship and ownership.

\section{Authors' contributions}

ZYW conceived of the study and designed all the experiments and drafted the manuscript. ZYW, GYF, SMW and DCQ performed the experiments. ZYW and ZQW performed the statistical analysis. ZQW and JC provided valuable insight for designing the study and revising the manuscript. All authors read and approved the final manuscript.

\section{Author details}

${ }^{1}$ Department of Pathogen Biology, School of Basic Medicine, Zhengzhou University, Zhengzhou 450001, China. ${ }^{2}$ Department of Clinical Laboratory, Henan Provincial People's Hospital, Zhengzhou 450003, China. ${ }^{3}$ Department of Clinical Laboratory, First Affiliated Hospital, Zhengzhou University, Zhengzhou 450052, China.

Received: 19 August 2012 Accepted: 22 January 2013

Published: 24 January 2013

\section{References}

1. Centers for Disease Control and Prevention: Sexually transmitted disease surveillance, 2009. Atlanta, GA: Centers for Disease Control and Prevention; 2011.

2. Madeleine MM, Anttila T, Schwartz SM, Saikku P, Leinonen M, Carter JJ, Wurscher M, Johnson LG, Galloway DA, Daling JR: Risk of cervical cancer associated with Chlamydia trachomatis antibodies by histology, HPV type and HPV cofactors. Int J Cancer 2007, 120:650-655.

3. Smith JS, Bosetti C, Muñoz N, Herrero R, Bosch FX, Eluf-Neto J, Meijer CJ, Van den Brule AJ, Franceschi S, Peeling RW: Chlamydia trachomatis and invasive cervical cancer: A pooled analysis of the IARC multicentric case-control study. Int J Cancer 2004, 111:431-439.

4. Joki-Korpela P, Sahrakorpi N, Halttunen M, Surcel HM, Paavonen J, Tiitinen A: The role of Chlamydia trachomatis infection in male infertility. Fertil Steril 2009, 91:1448-1450.

5. Malik A, Jain S, Rizvi M, Shukla I, Hakim S: Chlamydia trachomatis infection in women with secondary infertility. Fertil Steril 2009, 91:91-95.

6. Blas MM, Canchihuaman FA, Alva IE, Hawes SE: Pregnancy outcomes in women infected with Chlamydia trachomatis: a population-based cohort study in Washington State. Sex Transm Infect 2007, 83:314-318.

7. Medina M, Moya M, Hidalgo L, Calle A, Terán Eui P: Molecular identification of endocervical Chlamydia trachomatis infectionamong gestations at risk for preterm birth in Ecuador. Arch Gynecol Obstet 2009, 279:9-10.

8. Silveira MF, Ghanem KG, Erbelding EJ, Burke AE, Johnson HL, Singh RH, Zenilman JM: Chlamydia trachomatis in fection during pregnancy and the risk of preterm birth:a case-control study. Int J STD AIDS 2009, 20:465-469.

9. Wilkowska-Trojniel M, Zdrodowska-Stefanow B, Ostaszewska-Puchalska I, Redźko S, Przepieść J, Zdrodowski M: The influence of Chlamydia trachomatis infection on spontaneous abortions. Adv Med Sci 2009, 54:86-90.

10. Rours IG, Hammerschlag MR, Ott A, De Faber TJ, Verbrugh HA, de Groot R, Verkooyen RP: Chlamydia trachomatis as a cause of neonatal conjunctivitis in Dutch infants. Pediatrics 2008, 21:e321-e326.

11. Black CM: Current methods of laboratory diagnosis of Chlamydia trachomatis infections. Clin Microbiol Rev 1997, 10:160-184.
12. Manafi M: Fluorogenic and chromogenic enzyme substrates in culture media and identification tests. Int J Food Microbiol 1996, 31:45-58.

13. Orenga S, James AL, Manafi M, Perry JD, Pincus DH: Enzymatic substrates in microbiology. J Microbiol Methods 2009, 79:139-155.

14. Van Winkelhoff AJ, Clement M, De Graaff J: Rapid characterization of oral and nonoral pigmented Bacteroides species with the ATB anaerobes ID system. J Clin Microbiol 1988, 26:1063-1065.

15. Wohlsen TD: Comparative evaluation of chromogenic agar CM1046 and $\mathrm{mFC}$ agar for detection of $E$. coli and thermotolerant coliform bacteria from water samples. Lett Appl Microbiol 2011, 53:155-160.

16. Wang ZY, Kou J, Cui J, Wang ZQ: Chlamydia diagnosis method and reagent. China: CN patent 102286608A; 2011

17. Taylor-Robinson D, Thomas M, Dawson PL: The isolation of T-mycoplasmas from the urogenital tract of bulls. J Med Microbiol 1969, 2:527-533.

18. Berg ES, Anestad G, Moi H, Størvold G, Skaug K: False- negative results of a ligase chain reaction assay to detect Chlamydia trachomatis due to inhibitors in urine. Eur J Clin Microbiol Infect Dis 1997, 16:727-731.

19. Jang D, Sellors JW, Mahony JB, Pickard L, Chernesky MA: Effects of broadening the gold standard on the performance of a chemiluminometric immunoassay to detect Chlamydia trachomatis antigens in centrifuged first void urine and urethral swab samples from men. Sex Transmitted Dis 1992, 19:315-319.

20. Lee HH, Chernesky MA, Schachter J, Burczak JD, Andrews WW, Muldoon S, Leckie G, Stamm WE: Diagnosis of Chlamydia trachomatis genitourinary infection in women by ligase chain reaction assay of urine. Lancet 1995, 345:213-216.

21. Mahony JB, Chernesky MA: Effect of swab type and storage temperature on the isolation of Chlamydia trachomatis from clinical specimens. J Clin Microbiol 1985, 22:865-867.

22. Mårdh P, Zeeberg B: Toxic effect of sampling swabs and transportation test tubes on the formation of intracytoplasmic inclusions of Chlamydia trachomatis in McCoy cell cultures. Br J Vener Dis 1981, 57:268-272.

23. Ngeow YF: Limitations of serodiagnosis in chlamydial genital tract infections. Ann Acad Med Singapore 1996, 25:300-304.

24. Wang ZY, Fu GY, Chen RF, Qin Y: Fast diagnosis reagent for genital tract Chlamydia trachomatis. China: CN patent 1217004C; 2005.

25. Cheng A, Qian Q, Kirby JE: Evaluation of the Abbott RealTime CT/NG assay in comparison to the Roche cobas amplicor CT/NG assay. J Clin Microbiol 2011, 49:1294-1300.

26. Cosentino LA, Landers DV, Hillier SL: Detection of Chlamydia trachomatis and Neisseria gonorrhoeae by strand displacement amplification and relevance of the amplification control for use with vaginal swab specimens. J Clin Microbiol 2003, 41:3592-3596.

27. Jalal H, Al-Suwaine A, Stephen H, Carne C, Sonnex C: Comparative performance of the Roche COBAS Amplicor assay and in-house real-time PCR assay for diagnosis of Chlamydia trachomatis infection. J Med Microbiol 2007, 56:320-322.

28. Kerndt P, Ferrero DV, Aynalem G, Monga D, Wang S, Zhang N, Wong C, Liggins $M$, Meng $Q$ : First report of performance of the versant CT/GC DNA 1.0 Assay (KPCR) for detection of Chlamydia trachomatis and Neisseria gonorrhoeae. J Clin Microbiol 2011, 49:1347-1353.

29. Moller JK, Pedersen LN, Persson K: Comparison of the Abbott RealTime CT new formulation assay with two other commercial assays for detection of wild-type and new variant strains of Chlamydia trachomatis. J Clin Microbiol 2010, 48:440-443.

30. Pedersen LN, Pødenphant L, Møller JK: Highly discriminative genotyping of Chlamydia trachomatis using omp 1 and a set of variable number tandem repeats. Clin Microbiol Infect 2008, 14:644-652.

31. Greenwell P, Kakourou G, Raghooputh S: Analysis of glycosidases activity in Chlamydia trachomatis L2 Serotype. Int J med Update 2006, 1:25-32.

32. Siriwardena A, Strachan H, El-Daher S, Way G, Bryan W, Glushka J, Moremen K, Boons GJ: Potent and selective inhibition of class II a-D-mannosidase activity by a bicyclic sulfonium salt. ChemBioChem 2005, 6:845-848

33. Skudlarek MD, Orgebin-Crist MC: Effect of swainsonine on rat epididymal glycosidases. J Reprod Fert 1988, 84:611-617.

34. Tulsiani DR: Glycan-modifying enzymes in luminal fluid of the mammalian epididymis: an overview of their potential role in sperm maturation. Mol Cell Endocrinol 2006, 250:58-65.

35. Vázquez-Reyna AB, Balcázar-Orozco R, Flores-Carreón A: Biosynthesis of glycoproteins in Candida albicans: biochemical characterization of a soluble alpha-mannosidase. FEMS Microbiol Lett 1993, 106:321-325. 
36. Tulsiani DR, Skudlarek MD, Orgebin-Crist MC: Human sperm plasma membranes possess alpha-D-mannosidase activity but no galactosyltransferase activity. Biol Reprod 1990, 42:843-858.

37. Gao X, Chen XS, Yin YP, Zhong MY, Shi MQ, Wei WH, Chen Q, Peeling RW, Mabey D: Distribution study of Chlamydia trachomatis serovars among high-risk women in china performed using PCR-restriction fragment length polymorphism genotyping. J Clin Microbiol 2007, 45:1085-1089.

doi:10.1186/1471-2334-13-36

Cite this article as: Wang et al:: Rapid screening for Chlamydia

trachomatis infection by detecting a-mannosidase activity in urogenital tract specimens. BMC Infectious Diseases 2013 13:36.

\section{Submit your next manuscript to BioMed Central and take full advantage of:}

- Convenient online submission

- Thorough peer review

- No space constraints or color figure charges

- Immediate publication on acceptance

- Inclusion in PubMed, CAS, Scopus and Google Scholar

- Research which is freely available for redistribution 